\title{
Thermal Insulation Boards Based on Recycled Rigid Polyurethane Foam
}

\author{
Artur Miros ${ }^{1}$, Michał Kuzia ${ }^{2}$ \\ Łukasiewicz Research Network - Institute of Mechanised Construction \& Rock Mining, Branch in Katowice, \\ al. Korfantego 193 A, 40-157 Katowice, Poland, \\ a.miros@imbigs.pl \\ ${ }^{2}$ Kumbibex Sp. z o.o., \\ ul. Szkolna 8, 42-622 Orzech, Poland \\ michal.kuzia@kumibex.pl
}

\section{Extended Abstract}

From many years polyurethane products were often and commonly used in different fields of global market. Among various (included a lot of positive) aspects of wide use of polyurethane one of the negative effect is large amount of waste [1] (e.g. in Poland estimated amount of rigid polyurethane foam waste is c.a. 10000 tons per year). It is obvious that much more opportunity to re-use the PUR waste is for waste which comes directly from production line (clean, not contaminated PUR) instead of the PUR waste obtained from used, wasted different products. Not contaminated rigid polyurethane foam waste from production generally comes from two stages: preparing/starting of the production (on this stage adjustment of the production line parameters are made, at the beginning the polyurethane foam does not fulfil requirements of final product) and stage when product is cut on final dimensions (post-production cuttings).

This article presents one of the possibility of re-use the PUR waste from the production of the PUR sandwich thermal insulation panels which are coming straight from production line: obtaining thermal insulation boards based on recycled rigid polyurethane foam.

During PUR sandwich thermal insulation panels production some of the material is treated as a waste. Generally these polyurethane waste is in a form of different size PUR rigid pieces. The idea of obtaining thermal insulation boards from recycled rigid polyurethane foam is based on formation a mix consisting with PUR waste pieces and PUR foam as a bonding element [2].

The whole process of obtaining thermal insulation boards from recycled rigid polyurethane foam is divided on five steps: mechanical regrinding (pieces of PUR are mechanical regrinded on granulate with volume size c.a. from $1 \mathrm{~cm}^{3}$ to $10 \mathrm{~cm}^{3}$ ), drying by blowing (to obtain dry pieces without PUR dust - small particles below $1 \mathrm{~cm}^{3}$ of volume size), spraying PUR foam on pieces of granulates (bonding of PUR granulates) and forming final board.

The samples of the final thermal insulation board based on recycled rigid polyurethane foam (density of the samples from $50-60 \mathrm{~kg} / \mathrm{m}^{3}$ ) were subject of test investigation: dimensional stability, fire performance, long term water absorption, mechanical properties and thermal conductivity at mean temperature $10{ }^{\circ} \mathrm{C}$. Samples $(20$ boards with dimension: $100 \mathrm{x} 150$ $\mathrm{x} 10 \mathrm{~cm}$ ) were obtained from prototyped production line which consist mentioned five stages of production (construction of prototyped line was a part of PARP project [3]).

Obtained results show that such insulation board based on recycled rigid polyurethane foam (can by quite interesting alternative for the e.g. building applications. Results of dimensional stability, long term water absorption and mechanical properties allow to treat such product like a standard, factory made, rigid PUR board. Thermal conductivity value $\left(\lambda_{10} \approx\right.$ $0.027 \mathrm{~W} / \mathrm{m} \cdot \mathrm{K}$ ) places this product among quite good thermal insulating materials (lambda values for the most popular thermal insulating materials, EPS, MW are higher than $0.030 \mathrm{~W} / \mathrm{m} \cdot \mathrm{K}$ ). Due to the low reaction to fire classification (class F) the insulation board based on recycled rigid polyurethane foam can be applied for application where high fire class is not crucial, or as composite with coatings which lifts fire class of the whole product (e.g. OSB panels, steel claddings).

\section{References}

[1] K. M. Zia, H. N. Bhatti, I. A. Bhatti "Methods for polyurethane and polyurethane composites, recycling and recovery: A review," Reactive \& Functional Polymers, vol. 67 pp. 675-692, 2007. 
[2] J. O. Kuzia, "Method for producing structural heat-insulating board and the structural heat-insulating board," PL Patent Application 420868, March 16, 2017.

[3] PARP: POIR.02.03.02-24-0008/15-00 "Development of innovative technology for the processing of PU foam waste and new products for the construction industry." 